\title{
Una aproximación sociológica crítica activista al estudio de salud y migración: el caso ecuatoriano*
}

DOI: https://doi.org/10.18046/recs.i29.3481

\author{
A Critical Sociological Activist Approach to the Study \\ of Health and Migration: The Ecuadorian Case
}

\section{Roberta Villalón ${ }^{* *}$}

St. John's University (Nueva York, USA)

\footnotetext{
* Este artículo está basado en la investigación realizada entre los años 2015 y 2019, con el soporte de Fulbright Foreign Scholarship Grant (Council for International Exchange of Scholars), Sociologists for Women in Society (Social Action Award), RIID (Rielo Institute for Integral Development), St. John's University/Catholic Relief Services Global Faculty Grant, y la colaboración del Instituto de Salud y Migración del Hospital de la Universidad Técnica Particular de Loja, Ecuador. Artículo de investigación recibido el 18.03.2019 y aceptado el 07.08.2019.

** Profesora y directora del Departamento de Sociología y Antropología de la Facultad de Artes Liberales y Ciencias de St. John's University (Estados Unidos). Correo electrónico: villalor@stjohns.edu ORCID: https://orcid.org/oooo0oo2-6681-6286
} 


\section{Cómo citar/How to cite}

Villalón, Roberta (2019). Una aproximación sociológica crítica activista al estudio de salud y migración: el caso ecuatoriano. Revista CS, 29, 103-138. https://doi.org/10.18046/recs.i29.3481 
Los procesos migratorios ponen a prueba el bienestar físico, mental y emocional de los migrantes y los familiares que se quedan en el lugar de origen. Este artículo presenta una síntesis analítica de una investigación interdisciplinaria y aplicada entre 2015 y 2019 sobre migrantes ecuatorianos en Estados Unidos y España, familiares de migrantes en Ecuador, y migrantes retornados. Prestando atención a historias de salud y migración, dinámicas familiares, prácticas de cuidado, intersecciones transnacionales de estructuras sociales, y agencia individual y colectiva, el estudio identifica procesos en la salud y conceptualiza mecanismos psico-socioculturales que migrantes y familiares no migrantes emplean para lidiar con desafíos sanitarios relativos a la migración. Se discute cómo la aplicación de un marco teórico-práctico sociológico crítico, feminista y activista brinda una visión transformadora al estudio tradicional de salud y migración, eficaz para la prevención y tratamiento de los problemas de salud derivados de la migración.

PALABRAS CLAVE:

migración, salud, agencia, activismo académico, feminismo, Sur-Norte, Ecuador

Migratory processes test the physical, mental, and emotional well-being of migrants and their relatives that stay in their place of origin. This article presents an abridged analysis of an interdisciplinary and applied research developed between 2015 and 2019 about Ecuadorian migrants in the United States and Spain, relatives of migrants who stayed in Ecuador, and return migrants. By paying attention to health and migration histories, family dynamics, care practices, transnational intersections of social structures, and individual and collective agency, this study identifies health processes and conceptualizes psycho-sociocultural mechanisms that migrants and their relatives use to cope with migration-related health challenges. It discusses how the application of a critical, feminist, and activist theoretical-practical sociological approach provides a transformative vision to the traditional study of health and migration, which is effective to prevent and take care of health problems resulting from migration.

\section{KEYWORDS:}

Migration, Health, Agency, Activist Scholarship, Feminism, South-North, Ecuador 



\section{Introducción}

Los procesos migratorios ponen a prueba y, usualmente, afectan el bienestar de los migrantes y sus familiares. Por un lado, los migrantes pueden ver deteriorada su salud física y mental por las condiciones estresantes mismas de la migración. Por otro, aquellos migrantes que luego de unos o varios años regresan a su país, lo suelen hacer con un nivel de salud mental y física empeorada, más allá de su curso natural. Al mismo tiempo, los familiares de migrantes que permanecieron en su lugar oriundo tienden a pasar por dificultades emocionales que pueden desarrollar trastornos de comportamiento, psicológicos y físicos debido a la partida de sus parientes. Todos estos procesos tienen consecuencias no solo a nivel personal y familiar, sino también comunitario, generando un impacto en la salud pública de los países de salida, tránsito y llegada. Además, las condiciones de vida expulsoras de migrantes y familiares en sus países de origen; las incrementalmente precarias y peligrosas características de los viajes migratorios; y la creciente hostilidad hacia los migrantes en países de tránsito y llegada han deteriorado aún más la salud migrante en general.

Actualmente, los retos que los migrantes encuentran antes, durante y después de la migración están en aumento (World Health Organization, 2019). Sin embargo, no existen aún campañas públicas que difundan información sobre cómo la migración afecta la salud, ni existe coordinación entre políticas migratorias y sanitarias para mitigar las repercusiones negativas (por lo cual hay un nivel muy bajo de conciencia colectiva, prevención y acción sobre el tema). Asimismo, la conexión entre migración y salud raramente se incluye en la formación profesional de proveedores de salud o de servicios a migrantes; y esto, usualmente, se refleja en una atención deficiente, más allá de las buenas intenciones que los trabajadores puedan tener. Este dilema ha puesto en alerta a proveedores de servicios de salud y migratorios, especialmente a quienes se han dedicado a reducir las desigualdades sociales y sanitarias entre poblaciones migrantes y no migrantes.

Organizaciones en distintas partes del mundo, incluyendo, por ejemplo, la pionera Sociedad Italiana para la Medicina de la Migración (SIMM), la Plataforma Internacional de Cooperación para Migrantes Indocumentados (PICUM) y la Iniciativa de Salud de las Américas (ISA), han estado desarrollando estudios, proveyendo y promoviendo servicios de salud orientados a la comunidad migrante e intentando influenciar agendas políticas nacionales e internacionales desde abajo por varias décadas. Más recientemente, motivadas por la "crisis" de refugiados en Europa, la Organización Internacional para la Migración (OIM) y la Organización Mundial de la Salud (OMS) comenzaron a articular investigaciones y definir objetivos comunes, enfatizando el acceso igualitario a la salud para todo migrante, independientemente 
de su origen o estado legal, y motivando la provisión de servicios sanitarios cultural y lingüísticamente apropiados (International Organization for Migration [IOM], 2013); y, en 2016, la oficina europea de la OMS conformó el Knowledge Hub on Health and Migration, ofreciendo una plataforma bibliográfica y formativa para desarrollar programas de salud acordes a las necesidades de comunidades migrantes.

A pesar de estos esfuerzos para contrarrestar el hecho de que "la salud de los migrantes continúa siendo un tema desatendido" (IOM, 2018: 16), la brecha que existe entre las leyes internacionales y nacionales que establecen el derecho a la salud como derecho humano y su implementación todavía es tremendamente extensa. Los defensores del tema, convencidos de la gravedad del problema, están de acuerdo en que hay aún mucho camino que transitar para lograr reparar las desigualdades que afectan a la salud migrante, y consideran que tanto la investigación como el activismo son fundamentalmente estratégicos para el mejoramiento del bienestar de los migrantes, el avance de los derechos humanos y el desarrollo de la salud colectiva en general (The Health Initiative of the Americas, 2017).

\section{Generación del proyecto activista de salud y migración ecuatoriana: marco teórico-metodológico}

En línea con estos esfuerzos, en el año 2015, fui invitada a colaborar con una de las organizaciones que se ha focalizado en este problema: el Instituto para la Salud y la Migración del Hospital de la Universidad Técnica Particular de Loja, Ecuador ${ }^{1}$. Los procesos migratorios en este país han ocupado el centro de atención pública y académica en los últimos veinte años, particularmente a partir de la explosión emigratoria postcrisis económica de fines de le década de 1990, hacia España, Estados Unidos e Italia. Ecuador, de hecho, ha jugado todos los roles migratorios posibles: origen, destino y tránsito; mostrando altas tasas de migración interna interurbana y de áreas rurales a centros urbanos, así como también una peculiarmente alta tasa de migración de retorno debido a políticas de repatriación, ciudadanía universal y migración abierta (Falconí-Trávez, 2014; Herrera, 2008; Jokisch, 2014; Priblisky, 2004; 2007; Ramírez, 2013).

En el Instituto, trabajé junto a un grupo de profesionales sanitarios en el diseño de un proyecto de investigación con el fin último de prevenir, tratar y reducir los impactos negativos de la migración en la salud y, consecuentemente, ayudar a la disminución de las desigualdades de salud entre poblaciones migrantes y no mi- 
grantes, así como la promoción de la salud colectiva ${ }^{2}$. Los directivos del Instituto me convocaron por mi experiencia previa como investigadora-activista dedicada al tema de migrantes latinoamericanas y violencia de género, desde una perspectiva sociológica transnacional feminista (Villalón, 2010a, 2010b, 2011, 2014, 2015). Estaban convencidos de que para conseguir un entendimiento más acabado del tema y mejorar servicios, programas y políticas sanitarias, una perspectiva interdisciplinaria y aplicada era necesaria.

El activismo académico es una práctica "con una meta muy específica - la creación de cambio social”, en colaboración con la población involucrada en el estudio (Esterberg, 2002:136), y si bien el mismo no se rige por una definición o reglas fijas, ya que estas irían en contra del espíritu orgánico de la metodología y sus orígenes teóricos feministas y postcoloniales, la investigación activista se guía éticamente por los siguientes principios: 1 ) estar alerta a las relaciones de poder que se generan durante el proceso de investigación; 2) generar y mantener una relación democrática y abierta entre investigadores y participantes; 3) generar un modo colaborativo de producción de conocimiento desde la afirmación del poder y el saber de los participantes de la investigación, lo cual implica, entre otras cosas, el diseño de agendas de investigación en conjunto con el grupo, conversaciones a lo largo del proyecto, evaluaciones del estudio en su término y decisiones colectivas de publicación e implementación de programas o acciones; y 4) atender a las implicaciones políticas y aplicaciones prácticas del proyecto de investigación, con el fin de promover cambios sociales para el mejoramiento de las condiciones opresivas que afecten al grupo pertinente al estudio (Hale, 2008; Naples, 2003; Shayne, 2014; Villalón, 2014).

Desde este marco, mi participación brindó al proyecto una estructura amplia y transformadora, que combinó los beneficios de la propia extensión de la sociología (abarcadora de diversos factores demográficos, sociales, culturales, políticos, económicos y legales, entre otros, para el estudio de la migración y la salud en este caso) con la radicalidad del prisma interseccional del llamado feminismo de color, postcolonial y del sur global (Acker, 2006; Cho; Crenshaw; McCall, 2013; Crenshaw; Gotanda; Peller; Thomas, 1995; Hill-Collins, 1986; Martínez-Andrade, 2019; Roberts, 2002; Segato, 2003, 2016), incluyendo sus escritos de activismo académico (Jaggar, 2008; Naples, 2003; Shayne, 2014) y aquellos que aplican la interseccionalidad al estudio de salud (Hankivsky; Christoffersen, 2008; Navarro; Shi, 2001; Nazroo, 2003; Raphael, 2009; Williams, 2003); los estudios críticos de raza y migración (Castles, 2009; Glenn, 2000; Haney-Lopez, 1996; Hing, 2004; Johnson, 2007; Meñaca, 2006;

2. Los colegas del Instituto con quienes trabajé fueron el Dr. Riccardo Colasanti, la Dra. Johanna Montalvo, el Dr. Xavier Astudillo y la Dra. Yadira Gavilanes. También contamos con el apoyo de Marcelo Rodrigo como asistente de investigación en Loja, en el año 2017. 
Mooney, 2005; Navarro, 2009; Ong, 1999; Romero, 2008; Sánchez; Romero, 2010; Sayad, 2007; Villalón, 2015), la epidemiología crítica latinoamericana (Almeida-Filho, 1989; 200o; Breilh, 1977; 2003; 2010a; 2010b; 2013; Donnangelo, 1979; Krieger, 2012; Laurell, 1982; Samaja, 1992; Waitzkin; Iriart; Estrada; Lamadrid, 2001), y la antropología crítica médica (Biehl; Petryna, 2013; Brown et al., 2017; Castro; Singer, 2004; Farmer, 2001; Farmer; Kleinman; Yong-Kim; Basilico, 2017; Freund; McGuire; Podhurst, 2002; Illingworth; Parmet, 2017; Iriart; Waitzkin; Breilh; Estrada; Merhy, 2002; Renzaho, 2016; Singer; Baer, 2017).

El acercamiento particular que propuse ha representado un aporte a estudios realizados en esta línea crítica sobre migración, salud e inequidad, en contraste con el discurso dominante sobre el tema que, en general, carece de una dimensión histórica y política, y desestima cómo prácticas y sistemas sociales y culturales generan, reproducen y mantienen desigualdades de salud. Además, esta aproximación teórico-metodológica ha distinguido nuestra investigación de los estudios típicos de salud y migración, ya que estos se han realizado en su gran mayoría monodisciplinariamente, desde la medicina, la epidemiología, la psicología o la psiquiatría, enfatizando, a veces, cómo ciertas políticas sanitarias y migratorias afectan índices sanitarios específicos, y cuantitativamente, comparando poblaciones originarias con grupos migrantes. La aplicación crítica de la sociología y el feminismo postcolonial al estudio de la migración y la salud condujo al desarrollo de un proyecto interdisciplinario, activista y de métodos mixtos, incluyendo la recolección de datos a través de herramientas elaboradas en equipo, como encuestas, entrevistas semiestructuradas individuales y grupales, observación participativa, talleres grupales participativos, informativos y formativos, para migrantes y profesionales sanitarios, así como para proveedores de servicios migratorios.

Esta estrategia metodológica ha permitido la recolección de datos raramente buscados, los cuales, a través del análisis crítico, nos han llevado al desenmascaramiento de las raíces estructurales de procesos complejos de inequidad embebidos en comportamientos aparentemente inocuos y prácticas cotidianas de migrantes, familiares y proveedores de servicios de salud y migratorios. Así, el estudio no solo ha generado la elaboración, propuesta e implementación de medidas abarcadoras que prometen ser más operativas a la hora de lidiar con los problemas existentes, sino que también ha enfatizado la necesidad de publicar y difundir los resultados de la investigación accesible y abiertamente, a través de medios varios como radio, televisión, internet y encuentros comunitarios. Este acercamiento teórico-práctico fue desarrollado dentro de un marco ético, privilegiando los derechos inalienables de todo ser humano, sin perder de vista el bien común y las normas profesionales interdisciplinarias en cuanto a la seguridad, confidencialidad y claridad de/hacia 
los participantes. En cuanto a la coproducción del conocimiento resultante de la investigación, se mantuvieron los parámetros de fiabilidad, respeto y transparencia, con el fin último de eliminar el abuso de poder que puede generarse en los procesos de investigación sociales.

Además, el prisma utilizado ha permitido que las preguntas de la investigación fuesen más allá de lo descriptivo o de la corroboración de hipótesis preexistentes, para explorar cuestiones más extensas desde una perspectiva interseccional, esto es, teniendo en cuenta cómo varias estructuras y prácticas de poder influencian las oportunidades y capacidad de agencia de personas y grupos (Agustín, 2007; Crenshaw, 1995; Hill-Collins, 1998; Mahmood, 2001; Mani, 1998; Menon; Bhasin, 1998; Ortner, 2006; Romero, 2011; Spivak, 1988; Villalón, 2010b). A través del estudio en profundidad de cómo el bienestar de migrantes y familiares ecuatorianos fue afectado por procesos migratorios y cuáles fueron las maneras en que ellos lidiaron con los desafíos que se les presentaron, hemos planteado una serie de cuestiones teóricas, incluyendo: ¿cómo las desigualdades sociales a lo largo de las intersecciones de raza, etnia, nacionalidad, estado migratorio, género, sexualidad y clase en comunidades de origen, tránsito y receptoras dan forma a la experiencia migratoria y el desarrollo de la salud de los migrantes y sus familiares?; ¿cómo están vinculados los procesos nocivos y las desigualdades de salud con la violencia inherente a las disparidades estructurales, la marginalización interpersonal y los efectos de las diferencias culturales y la estratificación social en la provisión de servicios sanitarios?; ¿cómo se reflejan las ideologías políticas en el diseño de programas sanitarios, currículos educativos, investigaciones científicas, en general, y en la conceptualización misma del bienestar del migrante y la definición de trastornos a la salud y enfermedades, en particular?; ¿cómo es qué las políticas migratorias generan la jerarquización de seres humanos de acuerdo a su estado migratorio (migrante irregular, refugiado, asilado, etc.), así como reproducen o desafían procesos perniciosos, desigualdades de salud y salud colectiva? Al mismo tiempo, nos hemos concentrado en la agencia y el cambio social, analizando cómo la acción individual y colectiva puede afectar esos procesos de marginalización, y explorando cómo migrantes, familiares y proveedores sanitarios interactúan con y resisten procesos malsanos y desigualdades de salud. Por último, hemos examinado cómo todos estos mecanismos de marginalización pueden ser combatidos y desmantelados, con el objetivo de proponer modos alternativos para lidiar con los efectos que la migración tiene en la salud individual, familiar y colectiva, y así promover la igualdad.

En general, la aplicación de una perspectiva interdisciplinaria y crítica a la salud migrante reconoce las maneras en que sistemas estructurales de opresión intersectoriales dan forma al rango de agencia individual y colectiva, mientras que identifica el 
arraigamiento de estos esquemas divisivos en los pensamientos, prácticas, interacciones y creaciones tanto materiales como simbólicas de la gente. Adicionalmente, enfatiza la relevancia del pensamiento crítico, las movilizaciones sociales y el cambio social: el registro de la complejidad de la dominación estructural refuerza la capacidad de desafiar esos mismos sistemas, a través de esfuerzos conscientes personales y conjuntos. En otras palabras, esta perspectiva teórico-metodológica transforma las críticas en acción, dado que se apuesta a que, a pesar de las dificultades, todo sistema y prácticas opresivas pueden ser eventualmente desmantelados.

\section{Notas sobre la muestra y conceptos claves utilizados}

En este artículo, comparto resumidamente resultados primordiales del estudio y ofrezco mi análisis en el marco de la literatura existente y las preguntas guía de esta investigación activista del caso migratorio ecuatoriano ${ }^{3}$. Los datos han sido recolectados a través de esfuerzos de equipo en las ciudades de Loja y Santo Domingo, en Ecuador, sobre familiares de migrantes y migrantes retornados, y en las ciudades de Nueva York (Estados Unidos) y Cornellá de Llobregat (España) -importantes centros de recepción de población ecuatoriana, con no solo diferentes contextos culturales, sino también leyes migratorias y sanitarias-, sobre inmigrantes y sus familiares ya nacidos en estas localidades 4 . La muestra es no probabilística, de conveniencia, basada en técnicas de criterio selectivo teórico y bola de nieve. Los parámetros para la participación han estado abiertos simplemente a migrantes hombres y mujeres mayores de 18 años, y a proveedores de atención sanitaria y servicios migratorios a esta población en tres países. Esta amplitud nos ha permitido capturar variaciones importantes de acuerdo a género, composición familiar, etnia, nivel socioeconómico, desarrollo educativo, estado migratorio, años de migración, e historial médico y psicológico, entre otros. También la participación de migrantes de otros países latinoamericanos en encuestas y talleres comunitarios realizados nos ha servido de punto comparativo para contextualizar la experiencia ecuatoriana. Hasta la fecha

3. Para una versión extensa de los datos y el análisis, los invito a leer en un futuro próximo el manuscrito que estoy desarrollando actualmente: "Inequalities, Migration and Health: Critical Activist Research across Ecuadorean Borders”, a ser publicado por Bristol University Press.

4. Para desarrollar trabajo de campo en Ecuador, en los años 2016 y 2017, obtuve una Fulbright Foreign Scholarship Grant (Council for International Exchange of Scholars); para el trabajo de campo en España en el período 2017-2018, obtuve una St. John's University/Catholic Relief Services Global Faculty Grant. La Pontificia Universidad Católica de Ecuador, sede Santo Domingo, colaboró con la recolección de datos en Ecuador en el año 2017. La Dra. Laura Amado, de la Universidad Abat Oliba (Barcelona, España), ha colaborado también con la investigación en Santo Domingo, Ecuador y Cornellá de Llobregat, España. 
(agosto de 2019), recolectamos 400 encuestas a migrantes y familiares, 35 entrevistas individuales, 10 grupos focales, y notas de campo de 15 talleres comunitarios y un entrenamiento profesional de una semana de duración.

Hemos de notar que la definición adoptada de migrante (en vez de e- o in-) es deliberada, para incluir tanto los flujos emigratorios como los inmigratorios y de retorno, así como la condición asociada a parientes que no migraron, pero forman parte de familias transnacionales, no solo por razones descriptivas y etnográficas, sino también ideológicas: como bien argumentaría Sayad (2007:125) en su análisis sobre las múltiples paradojas, desafíos y valores de los seres humanos que se desplazan de sus comunidades de origen y viven en otros lugares del mundo, "el emigrante (que también es un inmigrante)" transcurre entre "formas incompletas de ausencia y presencia que eventualmente, tarde o temprano, se completarán". La migración es comprendida entonces como proceso y, así, como adjetivo que no define la esencia de una persona, familia, grupo o comunidad, sino que simplemente modifica su experiencia de diversas maneras. En cuanto a nuestra muestra, los participantes experimentaron un proceso migratorio desde el Sur al Norte Global (desde Ecuador hacia Estados Unidos y España), aunque luego, al estudiar los procesos de retorno, la experiencia fue la contraria, y en un contexto en el cual Ecuador atravesaba mejoras económicas y laborales substantivas, incluyendo políticas de repatriación prometedoras.

Prestando atención a historias de salud y migración, dinámicas familiares, prácticas de cuidado, intersecciones transnacionales de estructuras sociales y agencia individual y colectiva, el estudio identifica procesos en la salud y conceptualiza mecanismos psico-socioculturales que migrantes y familiares no migrantes emplean para lidiar con desafíos sanitarios relativos a la migración. La conceptualización de estos procesos y mecanismos, así como las reflexiones analíticas aquí presentadas texturizan y actualizan el conocimiento ya existente sobre el tema; además, brindan nuevas observaciones y definiciones relevantes tanto descriptiva como operacionalmente para prevenir y lidiar con los problemas generados por la migración en el bienestar y la salud de migrantes y familiares 5 . En el Cuadro 1, se incluye una lista comprensiva de los conceptos resultantes de esta investigación, indicando si son atravesados por los migrantes y/o los familiares no migrantes para facilitar la explicación y discusión de la próxima sección.

La conceptualización de los procesos y mecanismos presentados en el Cuadro 1 son el resultado analítico del conjunto de encuestas, entrevistas, grupos focales, talleres comunitarios y entrenamientos, articulando la literatura específica sobre

5. Es importante recalcar que el análisis de los datos aquí presentado ha sido desarrollado por mí misma con el consentimiento del equipo interdisciplinario y que el análisis en conjunto ha sido postergado por dificultades logísticas, pero se encuentra aún en nuestra agenda. 
\begin{tabular}{l|l} 
CUADRO 1 & $\begin{array}{l}\text { Conceptualizaciones de procesos en la salud y mecanismos } \\
\text { psico-socioculturales relativos a la migración }\end{array}$
\end{tabular}

\begin{tabular}{|c|c|c|}
\hline Procesos en la salud & Migrantes & Familiares \\
\hline Duelo reflexivo & $\mathrm{x}$ & $\mathrm{x}$ \\
\hline Trauma migrante activo & $\mathrm{x}$ & \\
\hline Trauma migrante pasivo & & $\mathrm{x}$ \\
\hline Estrés migratorio & $\mathrm{x}$ & $\mathrm{x}$ \\
\hline Disparadores de crisis migratorias & $\mathrm{x}$ & $\mathrm{x}$ \\
\hline Resiliencia irresoluta & $\mathrm{x}$ & $\mathrm{x}$ \\
\hline
\end{tabular}

Mecanismos psico-socioculturales

Migrantes | Familiares

\begin{tabular}{|c|c|c|}
\hline Ajustes a la desilusión & $\mathrm{x}$ & \\
\hline Salud migrante denegada & $\mathrm{x}$ & $\mathrm{x}$ \\
\hline Normalización del malestar & $\mathrm{x}$ & $\mathrm{x}$ \\
\hline Encapsulamiento del dolor & $\mathrm{x}$ & $\mathrm{x}$ \\
\hline De/re-construcción familiar & $\mathrm{x}$ & $\mathrm{x}$ \\
\hline Distorsión comunicativa & $\mathrm{x}$ & $\mathrm{x}$ \\
\hline Subordinación a secretos y mentiras & $\mathrm{x}$ & $\mathrm{x}$ \\
\hline Pactos tácitos & $\mathrm{x}$ & $\mathrm{x}$ \\
\hline Resentimiento y desapego & & $\mathrm{x}$ \\
\hline Comprensión sensata & $\mathrm{x}$ & $\mathrm{x}$ \\
\hline Ideal de bienestar & $\mathrm{x}$ & $\mathrm{x}$ \\
\hline Metas transgeneracionales & $\mathrm{x}$ & $\mathrm{x}$ \\
\hline Retorno estratégico & $\mathrm{x}$ & \\
\hline Retorno impuesto & $\mathrm{x}$ & \\
\hline Vergüenza del fracaso & $\mathrm{x}$ & \\
\hline Impactos del regreso & $\mathrm{x}$ & $\mathrm{x}$ \\
\hline
\end{tabular}

salud migrante con estudios sociológicos de migración, desde la perspectiva crítica interdisciplinaria indicada anteriormente. Nuestra muestra transnacional y comparativa indicó que estos procesos y mecanismos ocurrieron a migrantes y familiares independientemente del lugar de origen y el destino. Sin embargo, el modo y la intensidad con la que fueron atravesados fue diversa, dependiendo de sus condiciones personales y sociales previas a la partida (más o menos saludables y estables), lo sucedido en el transcurso del viaje migratorio (más o menos violento) y la situación posterior a la llegada-incluyendo el estado migratorio (regular/irregular), las políticas migratorias y culturas etnorraciales (más o menos inclusivas), el acceso a servicios 
sanitarios (públicos/privados, disponibles o no a migrantes), las circunstancias laborales (mejor o peores remuneradas, con o sin protecciones sociales y beneficios, más o menos explotadoras de la condición migrante), el ingreso y las remesas enviadas/ recibidas (bajo, medio o alto) y la movilidad social (personal y familiar, transnacional)-. Los lazos familiares, la edad, el género, y el nivel educativo también moldearon la manera en que migrantes y familiares atravesaron estos procesos y mecanismos.

Cabe notar también que, si bien estos conceptos surgen del estudio del caso ecuatoriano, la inclusión de otros participantes latinoamericanos en encuestas y talleres comunitarios, así como el entrenamiento a profesionales sanitarios y las entrevistas a proveedores de servicios a migrantes indican que los mismos procesos y mecanismos suelen también ser experimentados por migrantes de diversos orígenes nacionales y etnorraciales, particularmente en flujos migratorios desde Latinoamérica hacia Estados Unidos y Europa, y a la inversa, al retorno. A continuación, presentaré con más detalle, aunque aun resumidamente, los procesos en la salud y mecanismos psico-socioculturales migrantes identificados, en conversación con la literatura existente sobre el tema, para contextualizar su comprensión y el aporte teórico-práctico resultante de la perspectiva particular adoptada en esta investigación activista.

\section{Procesos en la salud y mecanismos psico-socioculturales derivados de la migración}

Para comenzar, nuestra investigación tuvo en cuenta la conocida "paradoja epidemiológica latina" o "efecto migrante sano" (el hecho de que grupos de inmigrantes latinoamericanos presentan menos prevalencia de problemas de salud crónicos que la población nacida en los Estados Unidos, explicado, mayoritariamente, por la juventud y buena salud con la que típicamente llegan los migrantes a ese país) (Cabieses, 2014; Rubalcava; Teruel; Thomas; Goldman, 20o8; Ullman; Goldman; Massey, 2011), y su modificación crítica, la hipótesis del "migrante saludable pero vulnerable", que señala cómo las duras condiciones de vida del migrante tarde o temprano afectan negativamente su salud (Caplan, 2007; La Parra-Casado; Mateo-Pérez; Albert-Guardiola; López, 20o7; Lara; Gamboa; Kahramanian; Morales; Hayes-Bautista, 2005; Miranda; Siddique; Der-Martirosian; Belin, 2005; Ríos-Marín; Hernández-Londoño, 2014). Los datos recogidos en nuestro estudio pusieron en cuestión la primera tendencia, y aportaron a la segunda.

En cuanto al efecto migrante sano, lo que se observó fue que si bien los ecuatorianos eran jóvenes y gozaban en general de buena salud, en creciente medida, tanto ellos como otros inmigrantes latinoamericanos llegaban a sus destinos con 
problemas de salud física y mental, dadas las crecientes carencias y dificultades en las que habían vivido en sus países nativos y las impericias a las que se enfrentaron en el trayecto, incluyendo enfermedades crónicas características de poblaciones con bajos recursos, lesiones físicas graves, mutilaciones, descompensaciones varias, enfermedades de transmisión sexual (resultantes, en general, de violencia por conflictos relacionados con el narcotráfico y la inseguridad civil, y violencia de género impartida antes de o durante el viaje) y, claro está, todos los efectos psicológicos del trauma sufrido (TEPT). Además, nuestra investigación indicó que, en la mayor parte de los casos, dado el estado irregular de los migrantes, las estadísticas en las que se basa el efecto migrante sano, son sesgadas.

En lo referido a la hipótesis del "migrante saludable pero vulnerable", nuestro estudio corroboró los problemas que debilitan la ya indicada supuesta salud inicial de esta población, y aportó comparaciones entre migrantes regulares e irregulares, a España y a Estados Unidos. Claramente, el tener un estado migratorio irregular incrementaba la vulnerabilidad de los migrantes en ambos países para los ecuatorianos, pero, en términos generales, Estados Unidos resultó más extenuante que España, debido a una combinación de factores. Por un lado, este último país presentaba un ambiente más conocido desde lo cultural (similitud idiomática e historia colonial) y acogedor desde lo político (leyes migratorias y sanitarias más abiertas y protectoras). Por otro lado, en la gran mayoría de los casos, los ecuatorianos en España gozaban de regularidad migratoria por un acuerdo bilateral que facilitaba el proceso, factor que se reflejó en nuestra muestra.

Los otros factores que incrementaron la fragilidad de los migrantes en ambos países (en mayor medida si eran irregulares, pero aun fuertemente si eran regulares) fueron relativos al trabajo: la segmentación del mercado laboral en los dos países llevó a estos migrantes (independientemente de su nivel educativo y experiencia previa) a trabajar en las áreas de la construcción (hombres), el servicio doméstico y hotelería (mujeres, limpieza, y cuidado de niños y ancianos), en restaurantes (hombres, empezando como lavavajillas, y mujeres, de meseras) y servicios de limpieza a empresas (género mixto, turnos de noche). Estos trabajos, en general, eran realizados sin contratos ni beneficios, y si bien en algunos casos pagaban mejor (construcción), en todos se trabajaban largas horas, sin descansos ni protecciones a los riesgos asociados a cada labor. La irregularidad incrementaba el miedo de los migrantes a ser delatados con las autoridades migratorias, por lo cual la demanda de mejores condiciones quedaba relegada. Nuestras entrevistas dejaron ver, sin embargo, que el miedo estaba presente aún en migrantes regulares, no por el riesgo a la deportación, sino a perder la posición que habían adquirido que, por más precaria y explotadora que fuese, tanto en España como en Estados Unidos, era mejor a la situación que 
tenían en Ecuador (todos lograban enviar remesas en el corto plazo, con un impacto muy significativo para la supervivencia de familiares, y hasta permitían el ahorro y la inversión en el mediano o largo plazo).

Las vulnerabilidades padecidas por los migrantes, que luego impactaban su bienestar mental y físico, fueron manejadas de un modo muy distinto de acuerdo al destino y el estado migratorio. En el caso español, los migrantes regulares e irregulares gozaban de la posibilidad de acceder a servicios de atención sanitaria sin costo alguno, y hacían uso de los mismos sin temor. Este sistema también facilitaba el tratamiento de casos urgentes resultantes de accidentes de trabajo, muy típicos en la construcción. Por el contrario, en Estados Unidos, los migrantes irregulares se vieron limitados a la utilización de los servicios de emergencia (que no requieren prueba de estado migratorio para ser atendido, no cobran al paciente si tiene bajos ingresos o proveen planes de pago, aunque a veces son imposibles de afrontar y dañan el crédito de los migrantes de por vida), y los migrantes regulares, que en su mayoría no tenían empleos formales de tiempo completo, no contaban con seguro de salud debido a su costo prohibitivo y, por lo tanto, utilizaban servicios privados, pero solo en casos de gravedad, dado su alto valor. En otras palabras, la salud se veía relegada a cálculos económicos cortoplacistas donde la prevención y la atención de trastornos menores era desechada con la esperanza de que se recuperarían naturalmente o se tratarían si pasaran a mayores condiciones, donde la asistencia médica fuera indispensable.

Otra observación resultante de nuestra investigación indicó que el padecimiento de enfermedades graves o la repetición de accidentes laborales eran disparadores del regreso ${ }^{6}$, ya que no solo se ve con ecuatorianos en España, sino que también aporta evidencia sobre migrantes que sufren accidentes, de los cuales suelen recuperarse bien físicamente, pero generan un replanteamiento del sentido del sacrificio emocional de vivir en condiciones altamente demandantes, mientras se encuentran solos o apartados de sus afectos familiares en sus países nativos. Es decir, en muchos casos, a diferencia de la conceptualización original que implica regresar a morir en la tierra donde se nació, lo que encontramos es que muchos migrantes también regresan a vivir, habiéndose recuperado de accidentes o enfermedades, y con una nueva escala de valores donde lo material no ocupa un lugar ya tan central, independientemente de la necesidad que aún tengan. Propongo entonces la modificación de ese concepto o la creación de otro que abarque este flujo migratorio, al cual podemos llamar

6. Este aspecto nos llevó a la revisión de la tesis llamada "Sesgo del Salmón” (Abraído-Lanza; Dohrenwend; Ng-Mak; Turner, 1999; Turra; Elo, 2008), que registra cómo migrantes latinos en Estados Unidos vuelven a sus países de origen cuando su salud se deteriora. 
“retorno estratégico". En este tipo de retorno, la decisión es tomada racionalmente, teniendo en cuenta varios factores, como refleja, por ejemplo, la respuesta que un joven que había emigrado a España con madre y padre dio para explicar por qué su familia había regresado a Ecuador después de vivir allí una década: "Por la crisis en España... especialmente para los hombres era difícil encontrar trabajo. Y mi papá ya estaba grande. Ya aquí [en Ecuador] ya teníamos hecha la casa... Mi madre aún trabajaba. Ellos dos lo conversaron, y decidieron regresar" (Familiar 287, comunicación personal, 2017) ${ }^{7}$. Este retorno debe ser entendido como un nuevo proceso migratorio que, a su vez, genera otra fase de adaptación y superación compleja (tanto de los migrantes como de los familiares que lo reciben), a la que sugiero conceptualizar como "impactos del regreso". Como claramente lo expresara la esposa de un migrante a España retornado:

Desde que mi marido regresó, se ha estado enfermando. De las amígdalas... ahora de las rodillas, los meniscos... Ha estado enfermo desde hace rato. Últimamente le duele la cintura, le duele también otra cosa... no sé qué. Mis hijas se peleaban cuando el regresó, y resentían que se había marchado. Pero también estaban agradecidas por lo que él había logrado para la familia... Decían que tenían miedo de ser muy amorosas y apegarse demasiado a él en caso que se volviese a ir... Ha sido bien difícil. Muy duro. Pero ahora estamos juntos. Ha sido duro también porque económicamente estamos luchando... pero mientras podamos comer antes de irnos a dormir estaremos bien. (Familiar 703, comunicación personal, 2016)

Aquí, quisiera notar que este tipo de (re)conceptualizaciones surge de la peculiar aproximación teórico-práctica de nuestra investigación, no solo por los resultados generados, sino también por la necesidad identificada de explorar cómo las teorizaciones existentes pueden ser, en sí mismas, controversiales o contraproducentes. La conceptualización y el lenguaje utilizado al rotular los procesos en la salud del migrante, a pesar de, tal vez, nutrirse de buenas intenciones, pueden tener un efecto contrario en las mismas poblaciones a las que se intenta favorecer sanitariamente, especialmente a través de cómo, desde el marco hegemónico de este campo (es decir, la biomedicina occidental, del Norte Global), se tiende a la patologización o a la búsqueda de razones extraordinarias para explicar la salud migrante. Propongo aquí cuatro ejemplos de este fenómeno: primero, la definición misma de la diferencia de mortalidad entre inmigrantes latinoamericanos y la población blanca oriunda de Estados Unidos como una "paradoja" y luego la búsqueda de explicaciones de la

7. Por cuestiones de confidencialidad, no se registraron los nombres de las personas entrevistadas ni se indican con exactitud las fechas ni el lugar donde se realizaron las entrevistas. 
misma incluyendo razones "obvias" como la edad de los migrantes y varios sesgos estadísticos del estudio original, y otras que, en modo racista (solapada o inconscientemente), buscan diferencias biológicas o genéticas -por ejemplo, con la tesis del "envejecimiento lento" (Horvath et al., 2016). Segundo, la comparación del comportamiento de la población migrante latinoamericana con procesos anómalos encontrados en animales (el sesgo del salmón). Tercero, la sobreestimación estereotípica de factores culturales -como al hacer referencia a la "supermaternidad" de las mujeres latinas y el llamado "familismo" como más nutritivos al crecimiento sano. Cuarto, el llamado "bonus del barrio," los beneficios que supuestamente trae el vivir en áreas residenciales de bajos recursos con residentes de habla hispana (Eschbach; Ostir; Patel; Markides; Goodwin, 2004), para comprender la (aún inexplicada y conjeturada) salubridad de esta población, a pesar de todas las desventajas en las que viven, dadas las peores condiciones socioeconómicas, de vivienda y de acceso a servicios sanitarios.

Con la intención de revertir los efectos nocivos de esas definiciones, recomiendo reconceptualizar al sesgo del salmón como parte del "retorno estratégico", dando así crédito al criterio utilizado por los migrantes que al enfermar o envejecer deciden regresar a sus países de origen con una revaloración de sus futuros. Este cambio humaniza, matiza y empodera a estos migrantes que definitivamente no están reaccionando animalísticamente para morir en su tierra, sino que están haciendo una evaluación racional y emocional sobre sus destinos, dados los cambios en su salud o las experiencias vividas en el exterior. Este tipo de re-humanización reinstaura la agencia de los migrantes y familiares, reconocida fundamentalmente en estudios feministas y teoría crítica racial y migratoria, que reconocen "el protagonismo que implica la decisión de migrar" (Agustín, 2006: 73).

A partir de la escucha y el análisis de las historias de migración y salud en nuestro estudio, surgió la necesidad de ajustar los llamados "duelo migratorio" y Síndrome de Ulises o "estrés crónico y múltiple" (Achotegui, 2004; Cuestas, 2011). Sugiero que, al primero, definido a partir del dolor que causa la partida y el alejamiento del lugar de origen y sus afectos, lo debemos, por un lado, desmitificar, y por otro, complicar. Los migrantes, si bien atraviesan un proceso de acomodación emocional a partir de la pérdida generada por la partida, no siempre lo que han dejado atrás es entrañable, por lo tanto, en muchos casos, más que un duelo, es una celebración de la superación conseguida por el simple hecho de partir. Esto ocurre en casos donde el migrante ha escapado de contextos de violencia (familiar o social) o dejado condiciones de severa o amenazante precariedad, como sucintamente lo expresara una migrante en Estados Unidos: "A pesar de todo, aquí estamos mejor. Cueste lo que cueste, allá no se podía estar tranquilo ni tener un futuro" (Migrante 324, comunicación personal, 
2018). En estas ocasiones, el duelo es un proceso que se había iniciado antes de migrar e inclusive que pudo haber contribuido a la misma decisión de partir, y las pérdidas son el lamentable resultado de una amplia gama de infortunios, desde sobrevivir a un hijo que mataron sin razón hasta convencerse de que será imposible lograr vivir con dignidad y en paz más allá de los esfuerzos personales y familiares realizados.

Además, el duelo migratorio también ocurre a las personas que regresan a su país de origen. El retorno, en sí mismo, puede ser el resultado de una decisión consciente y estratégica (el caso del "retorno estratégico" antes mencionado) o puede ser forzado como resultado de la deportación del migrante irregular o regular que fue sentenciado por su participación en actividades criminales, o de crisis laborales que traen una precariedad económica que les dificulta o impide la supervivencia en el país de destino (al que he llamado "retorno impuesto"). Sin duda, el trauma generado por ambos tipos de retorno es difícil de superar, sobre todo cuando los años pasados entre la partida y el regreso son muchos y las expectativas de los familiares que reciben al migrante retornado no fueron satisfechas, situación en la cual el retornado sufre de lo que denomino "vergüenza del fracaso". Tanto migrantes retornados como familiares atraviesan un proceso de reacomodación que, en muchos casos, es conflictivo. Las reunificaciones no exitosas afectan especialmente la salud del migrante retornado, quien seguidamente intenta hacer un nuevo intento migratorio, el cual, una vez más, genera nuevos duelos para el que vuelve a partir y los que vuelven a quedarse. En general, los duelos de los migrantes y sus familiares deberían considerarse como procesos de aprendizaje a partir y más allá de lo emotivo, como una persona encuestada acerca de la descripción de la migración como un duelo escribió: "Siempre lo expliqué como una muerte y un renacer, de alguna forma mueren muchas cosas y surgen otras nuevas. El proceso es muy duro, pero cuando se logra salir es satisfactorio y uno queda más reforzado. La migración me ha ayudado a crecer como ser humano" (Migrante 857, comunicación personal, 2018). Basado en estas cualificaciones, modifico al duelo migratorio como "duelo reflexivo".

Similarmente, sugiero que el llamado estrés crónico y múltiple, resultante de la incapacidad de elaboración del duelo migratorio en migrantes transcontinentales, sea matizado, principalmente porque, como he dicho, los conflictos y pérdidas a superar no solo o siempre están vinculadas directamente a la partida y, además, porque a menudo los trastornos psicológicos y físicos asociados a este estrés (síntomas depresivos, ansiosos, cognitivos y somáticos) suceden como resultado de las condiciones de vida extenuantes en el país de destino, los problemas acontecidos en tránsito (incrementalmente amenazante, violento y riesgoso), la desilusión experimentada por los migrantes, quienes, ya sea por un mecanismo de defensa o por falta de información, habían sobredimensionado lo fantástico que sería vivir en otro 
lugar y minimizado lo difícil que sería el traslado y comenzar de nuevo en tierras lejanas y culturas extrañas (proceso al que llamo “ajustes a la desilusión”), y las dificultades asociadas a los retornos. Por lo tanto, recomiendo que el rótulo Síndrome de Ulises sea reservado para los casos extremos teorizados por Achotegui (2004; 2009), y que el estrés crónico y múltiple sea ampliado como "estrés migratorio", en casos más moderados, asegurándose la diferenciación de las causas y síntomas del mismo entre duelos no elaborados por eventos previos a la migración, propios del viaje, postmigratorios y de retorno.

Dentro de este marco ampliado sobre cómo el bienestar psicológico y físico es afectado por la migración, es de destacar que la definición epidemiológica de la misma, como factor de riesgo (circunstancia o situación que incrementa las probabilidades de contraer problemas de salud o enfermedades) (Organización Mundial de la Salud, 2017), siempre debe contextualizarse personal, histórica y sociopolíticamente. En otras palabras, además de tener en cuenta la historia clínica del migrante y sus familiares, hay que contextualizar su experiencia en los lugares de origen, tránsito y destino, para comprender los varios disparadores de procesos traumáticos y los elementos sociales, culturales, legales, políticos y económicos que restringen o facilitan su superación. En nuestro estudio, observamos cómo la migración se manifestó como un proceso que, indudablemente, puso a prueba la entereza tanto de los migrantes como de sus familiares no migrantes (a los que he llamado, respectivamente, "trauma migrante activo" y "trauma migrante pasivo"), la cual, usualmente, ya se encontraba debilitada, creando una capa extra de tensión que ocasionalmente revivía problemas existentes previos a la migración. Por ejemplo, una mujer que fue a España a reencontrarse con su pareja expresa ilustrativamente el trauma migrante activo:

Fue muy duro. Sentía una soledad que era inexplicable, un vacío inexplicable. Como un dolor de muela que está ahí latiendo, latiendo y latiendo, pero no tiene cura. A pesar de que estaba con mi marido y luego en gestación, no se me podía ir la tristeza. Cuando estaba con esa tristeza tan grande, ni quería llamar a mi familia en Ecuador para no remover la añoranza que sentía. La tristeza, la depresión, me afectó el embarazo. (Migrante 133, comunicación personal, 2016)

Y un joven que recuerda lo que le sucedió de pequeño al partir sus padres refleja, claramente, el trauma migrante pasivo:

- Porque cuando me quedé aquí me empecé a enfermar...como no tenía a mis padres.

Me decían que estaba triste...

-¿De qué te enfermaste? 
- Por ejemplo... tuve... no sé, no sé cómo explicarlo... Por un momento sufría de los huesos, no sé, no sé... me ponía débil, no sé por qué, e incluso me quedé... ¿cómo se dice?... ¿parapléjico? o algo así... porque no podía mover esta pierna... se me quedó inmóvil. (Familiar 585, comunicación personal, 2017)

Migrantes, familiares y retornados surcaron procesos de "de/re-construcción familiar" donde dinámicas y patrones íntimos se desarmaban y rearmaban de acuerdo a los miembros que partían, los que tomaban posiciones de autoridad, los que se sumaban y los que regresaban. Si bien estos cambios familiares eran entendidos como propios de la migración, percibidos como inevitables y aceptados -a lo cual denomino "comprensión sensata"-, generaban una serie de sentimientos encontrados a partir de la justificación de la separación como un acto de cuidado para lograr la supervivencia o prosperidad familiar. Los migrantes estaban conflictuados por la carga emocional de ser los responsables de sostener o salvar a la familia-amor, compromiso, duda de ser capaces, tristeza, soledad y miedo que, en general, resultaba en complejos sentimientos de culpa-. Los hijos e hijas de padres y madres que se habían ido cuando eran muy pequeños sentían, principalmente, respeto por sus padres por los esfuerzos realizados (sobre todo si los familiares a cargo les enseñaban a reconocerlos); sin embargo, también sentían resentimiento y desapego, y no estaban de acuerdo con la decisión que sus padres habían tomado porque, para ellos, el costo emocional que habían sufrido por la partida no era comparable a los avances económicos que percibían. Por su parte, los hijos e hijas que eran más grandes sí solían sentir afecto por sus padres, aunque también mantenían una cuota significativa de rencor y coincidían en que el costo emocional de la migración no valía la pena.

En el caso de las parejas que se separaban, el estar completamente de acuerdo en la partida y el regreso les ayudaba a sostener la relación a larga distancia sin tanto disgusto. No obstante, comúnmente el migrante terminaba por extender su estadía en el exterior, lo que tensionaba las cosas y, a veces, incluso formaba una nueva pareja y familia paralela (lo que intentaba ocultar, pero indefectiblemente afectaba la unión original). En estos casos, el que se había quedado se sentía traicionado y enojado, pero también desarrollaba sentimientos de culpa (creían haber cometido un gran error al haber permitido la partida), y similarmente a los hijos, se convencían de que migrar representaba finalmente demasiados sacrificios y problemas. De hecho, una de las recomendaciones más comunes que migrantes, familiares y retornados hacían a quienes estuviesen considerando migrar, en las encuestas, entrevistas y grupos focales realizados, era: "no lo hagan al menos que se fuesen juntos, en familia y se mantengan unidos" (Migrante 473, comunicación personal, 2017). Ningún participante que había pasado por la separación familiar a 
causa de la migración consideraba, en retrospectiva, que la prosperidad lograda, por más mínima o extravagante que fuese, compensaba lo que se había perdido como resultado del apartamiento.

La complejidad de los procesos de deconstrucción y reconstrucción familiares no puede ser resumida en solo una cita; sin embargo, esta narración de una mujer entrevistada sobre su experiencia familiar migratoria refleja bastantes aspectos claves:

El hermano de mi marido también emigró. Primero, se fue solo. Después, se fue la esposa, dejando a sus dos hijas con su abuela. Después de unos años, se llevaron a las hijas a España, porque creían que, si no lo hacían, ellas no los iban a querer más. Luego, en uno de los viajes de visita a Ecuador, las hijas le pidieron a su abuela que querían quedarse con ella y no regresar a España con sus padres porque la habían pasado fatal allí. Se sentían extrañas con su padre, a quien no conocían realmente porque no habían crecido con él. También habían sido maltratadas por su nueva hermana que había nacido en España mientras ellas aún vivían en Ecuador. Ella les decía que tenían que regresarse a Ecuador porque esos eran sus padres y no los de ellas. La hermana les pegaba y trataba muy mal. Las dos niñas se sentaban en un rincón y lloraban, pidiendo regresar a Ecuador. Pero no podían hacerlo ni se lo permitían. Eran menores. (Familiar 367, comunicación personal, 2016)

Las dificultades asociadas con la migración también se reflejaron en nuestro estudio, al registrar que, comúnmente, tanto los migrantes como los familiares que se quedaron en sus lugares de origen atravesaron procesos arduos de estrés migratorio activo y pasivo, respectivamente, con síntomas de las áreas depresiva (profunda tristeza y largas horas de llanto), de la ansiedad (insomnio, tensión, pensamientos recurrentes e intrusivos, e irritabilidad), confusional (falta de concentración y atención, pérdida de la noción del tiempo, fechas y lugares, y olvido) o psicosomáticas (dolores corporales, cefalea, cambios de apetito), que con más o menos rapidez fueron desapareciendo. El Cuadro 2 presenta las estadísticas descriptivas referidas a este punto, resultantes de la encuesta en la que se incluyeron preguntas sobre estos síntomas basados en la literatura existente sobre el tema (Achotegui, 2004; 2009; Caplan, 2007; La Parra-Casado et al., 2007; Lara et al., 2005; Miranda et al., 2005; Ríos-Marín; Hernández-Londoño, 2014).

Muy sintéticamente, estas estadísticas muestran que, en términos generales, más de la mitad (a veces casi tres cuartos) de los migrantes reportaron haber tenido estos síntomas con frecuencia o algunas veces, en oposición a nunca (con la única excepción de pensamientos suicidas); y que, en el caso de los familiares no migrantes, más de la mitad reportó haber tenido los síntomas de tristeza, llanto, tensión y fatiga con frecuencia o algunas veces, en oposición a nunca (esta diferencia se 
\begin{tabular}{l|l} 
CUADRO 2 & Estrés migratorio y cambios en la salud
\end{tabular}

Síntomas estrés migratorio $\quad$ Migrantes $\quad$ Familiares no migrantes

\begin{tabular}{|c|c|c|c|c|c|c|}
\hline & $\begin{array}{c}\text { Con } \\
\text { frecuencia }\end{array}$ & $\begin{array}{l}\text { Algunas } \\
\text { veces }\end{array}$ & Nunca & $\begin{array}{c}\text { Con } \\
\text { frecuencia }\end{array}$ & $\begin{array}{l}\text { Algunas } \\
\text { veces }\end{array}$ & Nunca \\
\hline Tristeza & $31,4 \%$ & $56,8 \%$ & $11,9 \%$ & $19,3 \%$ & $56,3 \%$ & $24,4 \%$ \\
\hline Llanto & $21,6 \%$ & $51,4 \%$ & $27 \%$ & $9,2 \%$ & $44,2 \%$ & $46,7 \%$ \\
\hline Tensión & $25,5 \%$ & $52,1 \%$ & $22,3 \%$ & $12,4 \%$ & $40,5 \%$ & $47,1 \%$ \\
\hline Insomnio & $24,2 \%$ & $41,9 \%$ & $33,9 \%$ & $10 \%$ & $35 \%$ & $55 \%$ \\
\hline Pesadillas & $5,4 \%$ & $44 \%$ & $50,5 \%$ & $5 \%$ & $26,9 \%$ & $68,1 \%$ \\
\hline Pensamientos repetitivos, intrusivos & $14 \%$ & $46,8 \%$ & $39,2 \%$ & $11,1 \%$ & $23,1 \%$ & $65,8 \%$ \\
\hline Irritabilidad, nerviosismo & $17,8 \%$ & $56,2 \%$ & $25,9 \%$ & $12,6 \%$ & $26,9 \%$ & $60,5 \%$ \\
\hline Fatiga & $26,8 \%$ & $45,4 \%$ & $27,9 \%$ & $11 \%$ & $39,8 \%$ & $49,2 \%$ \\
\hline Dolores corporales & $20,8 \%$ & $44,8 \%$ & $34,4 \%$ & $6,7 \%$ & $29,2 \%$ & $64,2 \%$ \\
\hline Confusión, distracción, despiste & $14,4 \%$ & $30,9 \%$ & $54,8 \%$ & $6,7 \%$ & $40 \%$ & $53,3 \%$ \\
\hline Pensamientos suicidas & $2,7 \%$ & $8,7 \%$ & $88,6 \%$ & $5 \%$ & $5,8 \%$ & $89,2 \%$ \\
\hline \multirow[t]{2}{*}{ Apetito } & Descenso & Ascenso & $\begin{array}{c}\text { Sin } \\
\text { cambio }\end{array}$ & Descenso & Ascenso & $\begin{array}{c}\text { Sin } \\
\text { cambio }\end{array}$ \\
\hline & $18,8 \%$ & $29,6 \%$ & $51,6 \%$ & $16,9 \%$ & $9,3 \%$ & $73,7 \%$ \\
\hline $\mathrm{N}$ & \multicolumn{3}{|c|}{226} & \multicolumn{3}{|c|}{127} \\
\hline \multirow{2}{*}{ Estado de salud premigratorio } & Excelente & Bueno & Débil & Excelente & Bueno & Débil \\
\hline & $51,6 \%$ & $47,3 \%$ & $1,1 \%$ & $44,5 \%$ & $51,3 \%$ & $4,2 \%$ \\
\hline \multirow{2}{*}{$\begin{array}{l}\text { Cambios postmigratorios } \\
\text { en la salud }\end{array}$} & Sí & & No & Sí & & No \\
\hline & $47,8 \%$ & & $2,2 \%$ & $22 \%$ & & $78 \%$ \\
\hline
\end{tabular}

asocia con que la muestra de familiares encuestados eran de menor edad). La otra observación notable se vincula con que, a pesar de que la gran mayoría padeció una serie de síntomas vinculados con el estrés migratorio, una menor proporción reportó haber percibido cambios en su salud, lo que en combinación con las entrevistas en profundidad y grupos focales realizados conlleva a las conceptualizaciones "salud migrante denegada" y "normalización del malestar", es decir, la desestimación y codificación de síntomas como propios a la migración. Por ejemplo, en todas las entrevistas individuales realizadas, los migrantes y familiares afirmaron que a ellos no les pasaba nada con su salud, aunque luego, al avanzar con preguntas más específicas, hablaron de noches en velo, llantos diarios, falta de ánimo e, incluso, varias complicaciones como presión arterial, colesterol y diabetes. Sin embargo, no asociaron las mismas con la migración y lo catalogaron como normal. Similarmente, como expresara una migrante a España en un grupo focal: 
Yo me sentía terriblemente mal. Estaba tan triste que lloraba todas las noches; no podía dormir. Igualmente trabajaba todo el día. No le contaba nada a nadie. Pensé que era normal. ¿Cómo no iba a estar así, lejos de mi país, de mi familia? Estuve así meses de meses. Hasta que un día ya no podía ni salir de la cama, y la señora que me empleaba me sugirió que fuese al centro de atención primaria porque pensó que tenía fiebre o algo. Me diagnosticaron una depresión severa y recomendaron tratamiento. (Migrante 294, comunicación personal, 2017)

Considero que ambos procesos, el de denegación y normalización, están arraigados a un marco sociocultural, político y legal que, históricamente, por un lado, ha sobrevaluado la perspectiva biomédica de la salud que se focaliza en la patología y estigmatiza la salud mental; y por otro lado, dedica la atención de la salud migrante para la prevención de enfermedades exóticas y tropicales, identificando al migrante como vector de enfermedades infecciosas, en vez de reconocer las maneras más levese inocuas en que la migración afecta su salud y también la de sus familiares no migrantes.

En términos generales, los migrantes y familiares que lograron superar el trauma migratorio más rápidamente mostraron gran capacidad de adaptación y progreso, e inventiva, con casos donde la autonomía e independencia fueron claves y notables, sobre todo en niños y jóvenes; y con otros donde la intervención de personas (cercanas, como familiares, o más lejanas, como maestros) que les ofrecieron apoyo emocional y soporte logístico fue el punto de inflexión para transformar el curso de las cosas. En general, también, estos migrantes se aferraron a su trabajo o al estudio (si migraban en edad escolar) encontrando en la actividad diaria (de largas horas) distracción, tranquilidad y, además, una legitimización de la razón por la cual habían partido. Estas características y tácticas han sido asociadas, en la literatura, a la resiliencia (Bourbeau, 2015; Southwick; Bonanno; Masten; Panter-Brick; Yehuda, 2014). Sin embargo, en nuestro estudio las mismas no indicaban que estos migrantes y sus familiares no migrantes fuesen o se considerasen resilientes. De hecho, a la pregunta que se les hizo en entrevistas de profundidad, casi la totalidad respondió contundentemente que "no" se sentían resilientes, sino, a lo sumo, "resistentes", porque si bien habían logrado aguantar las dificultades hasta entonces presentadas, dadas la fatiga de los esfuerzos realizados y las fuertes exigencias e incertidumbre en las que aún vivían, ya fuera en sus lugares de destino u origen, no lograban sentirse más fuertes que antes. Solo sabían que deberían seguir resistiendo y que su éxito futuro no era claro, más allá de su bienestar actual y la movilidad social que hubiesen logrado -a esto lo he denominado "resiliencia irresoluta".

Inclusive, frecuentemente notamos el definido "encapsulamiento del dolor"; es decir, un proceso a través del cual los migrantes y familiares contenían y apartaban los sentimientos angustiantes relativos a la partida para "seguir adelante" sin ne- 
cesidad de elaborar (psicológicamente hablando) el trauma. Este encapsulamiento estaba acompañado por lo que he conceptualizado como "ideal de bienestar", que se manifestaba en fuerza y perseverancia en hacerle frente a padecimientos e inconvenientes, con la convicción de que tarde o temprano verían los frutos de su esfuerzo al alcanzar un estado de bienestar a nivel personal y, especialmente, familiar, ya que las metas eran generalmente planteadas como "metas transgeneracionales": "Al final, todos estos sacrificios son por nuestros hijos, por su futuro. Hay que salir adelante. Hay que hacerle" (Migrante 528, comunicación personal, 2018).

En este ávido intento de superación, notamos otro proceso que he denominado "subordinación a secretos y mentiras", donde se mantenían y rearmaban "pactos tácitos" entre familiares en el exterior y en los países oriundos, para no cuestionar el ocultamiento o la deformación de información como práctica común de comunicación, con el objetivo de seguir persiguiendo su mayor meta. Este tipo de "distorsión comunicativa" acerca de las experiencias vividas, era justificada por ambas partes como una herramienta válida y necesaria para lograr salir adelante. Por ejemplo, el familiar que sufría profundamente nunca lo decía a su contraparte para no preocuparla, y esta no lo disputaba porque no creía poder ayudarlo desde la lejanía; además, ambos estaban convencidos de que no era útil insistir en lo negativo, sino concentrarse en lo positivo. Como lo dijo una mujer entrevistada que era parte de una familia con miembros emigrados a Estados Unidos:

Siempre están preocupados, todos, los que se fueron y los que se quedaron. Aunque hablan por teléfono, no es lo mismo. Siempre se dicen que todo está bien, pero en realidad no se dicen lo que pasa, ni se sabe la verdad. Igualmente, nadie se queja de que sea así. (Familiar 723, comunicación personal, 2016)

Tanto el encapsulamiento del dolor como las tres últimas prácticas mencionadas eran funcionales en el corto y mediano plazo; sin embargo, tenían su efecto contraproducente: el acontecimiento de ciertos eventos años después de la partida, que he conceptualizado como "disparadores de crisis migratorias", como graduaciones, casamientos y fallecimientos, podía desestabilizar el estado de normalidad conseguido, creando nuevos conflictos familiares (donde se reprochaban los secretos y las mentiras) y disparando el resurgimiento de los síntomas postraumáticos que a veces derivaban en complicaciones graves.

Por su parte, las capacidades de resistencia y resiliencia se veían aún más necesitadas en los casos de migrantes y familiares que vieron los síndromes del trauma migratorio perdurar en el tiempo o resurgir, y complejizarse. En estos casos más severos, nuestro estudio encontró que el llanto y la tristeza eran paralizantes, transformándose en depresión clínica a veces con tendencias suicidas, o en adicciones 
al alcohol o las drogas; la ansiedad llevaba a ataques de nervios o de pánico; la confusión espaciotemporal, a la incapacidad de lidiar con el día a día; la irritabilidad, a la violencia y agresión a otros; las manifestaciones corporales se agravaban hacia la fatiga, migrañas y dolores inmovilizadores impidiendo la continuación normal de actividades; los cambios de apetito se traducían en cambios de peso hacia la obesidad, alto colesterol, hipertensión arterial, diabetes y el desarrollo de problemas digestivos, como gastritis y úlceras; y también aparecían problemas respiratorios, como asma, y dermatológicos, como alopecia.

La superación de estos problemas de salud fue lograda a partir de tratamientos médicos y psicológicos, los cuales, como antes mencioné, fueron más factibles y menos onerosos para los migrantes en España que en Estados Unidos, y más accesibles para familiares de migrantes con mayores niveles educativos o en mejores condiciones económicas en Ecuador. En estos casos, la intervención de familiares (parejas, tíos o primos, para migrantes; y abuelas o tías, para familiares) y maestros de la escuela o empleadores cumplió un papel clave para motivar el inicio y luego mantener los tratamientos, ya que los que se encontraban inmersos en estos problemas solían minimizarlos o negarlos, o ya dependían del cuidado de otro porque se hallaban en una situación de debilidad que les generaba incapacidad. El apoyo médico y psicológico recibido por estos migrantes y familiares no migrantes fue más fructífero cuando los proveedores de servicios tenían una sensibilidad y formación relativa a la salud migrante, debido a que tomaban a la migración misma o de los familiares del paciente como un punto clave en su diagnóstico y tratamiento. Lamentablemente, una gran proporción de los participantes de nuestra investigación no contó con esta ventaja y padeció de diagnósticos errados y tratamientos inútiles - de allí la insistencia de nuestro equipo en la difusión de la información a la comunidad, el diseño curricular para la formación profesional, y la creación de políticas sanitarias y migratorias que tengan en cuenta su vínculo-.

Estas iniciativas mejorarían los problemas presentados en el llamado "Síndrome de Salgari" (Geraci, 2006), que describe los efectos negativos que las expectativas desencontradas entre pacientes procedentes de orígenes menos desarrollados y profesionales sanitarios en países más desarrollados tienen para el diagnóstico y el tratamiento. De hecho, nuestro estudio propone también refinar el entendimiento de la relación médico-paciente, replanteándolo con base en las experiencias de migrantes oriundos de América Latina, y sanitarios en Estados Unidos y España. En comparación a lo que Geraci (2006) indicaba en el caso de migrantes del continente africano en Italia, nuestra investigación halló que, por un lado, muchos pacientes migrantes no estaban convencidos de la eficiencia médica de los países de destino e, inclusive, desconfiaban de la capacidad del profesional para comprenderlos. 
Por otro lado, a pesar de que muchos médicos asumían que los pacientes migrantes estaban en condiciones de inferioridad cultural dado su origen y dudaban de su capacidad intelectual y cognitiva, en pocas ocasiones creían que estos pacientes representarían casos médicos extraordinarios o exóticos. En general, los médicos no mostraban entusiasmo alguno en el tratamiento de pacientes migrantes, sino más bien desinterés dada la normalidad o poca seriedad de los casos que presentaban. Es decir que, en el caso de migrantes latinoamericanos en Estados Unidos y España, la discrepancia básica observada en la relación médico-paciente se caracterizaba por el desprecio y la desconfianza que suele tener el uno del otro; de este modo, más que fascinación por lo exótico y desilusiones (a lo que el rótulo de Salgari hace referencia), se trataba de una relación desbalanceada, basada en la subestimación y la sospecha. Esta relación médico-paciente migrante, a la que he denominado "descalificación mutua", también generaba efectos contraproducentes, incluyendo diagnósticos desacertados y tratamientos inconclusos.

En lo relativo a los profesionales sanitarios, nuestra investigación también encontró una "desazón latente". En general, ellos estaban insatisfechos con sus pacientes migrantes y familiares de migrantes. Esto sucedía con profesionales conscientes de que lo que les sucedía estaba relacionado con la migración y no podía curarse con medicaciones o tratamiento médico, como lo expresara una profesional sanitaria española: "Es que vienen a consultarnos por todo tipo de dolencias que son nada... pues, problemas migratorios... ¿y que hemos de hacer nosotros? Eso no se cura médicamente, eso es social, político, económico. No es al centro sanitario que deberían ir" (Profesional sanitario 437, comunicación personal, 2018). También la desazón se presentaba en proveedores de salud que no estaban al tanto o no daban crédito a esta relación y, consecuentemente, estaban molestos con la insistencia de los pacientes que se quejaban de múltiples dolencias y retornaban con nuevas sin responder a lo prescrito (que era errado o incompleto). Como dijo un médico en Ecuador: "No entiendo qué le pasa exactamente. No se cura. No hace caso. Vuelve a verme y seguimos en cero. Siempre tiene algo nuevo" (Profesional sanitario 364, comunicación personal, 2017). Esta desazón generaba, a veces, leves, pero también serias consecuencias en el modo como migrantes y familiares no migrantes eran atendidos, y en el camino hacia la superación de sus problemas de salud vinculados con los procesos migratorios.

Asimismo, los proveedores conscientes de la salud migrante compartían con los de otros servicios la llamada "esperanza moderada" acerca del impacto o éxito que su asistencia podía tener para la solución de los padecimientos de sus pacientes o beneficiarios. La moderación resultaba de su realista evaluación de la fuerza restrictiva de ciertos factores estructurales que, simplemente, eran inmunes a las acciones 
a nivel personal, sobre todo en situaciones en las que el migrante y sus familiares se encontraban en condiciones críticas, y cuando el contexto político y legal se tornaba más excluyente y opresivo. Una psicóloga dedicada a la atención migrante en Estados Unidos, por ejemplo, compartió durante la entrevista su temor:

Es muy difícil mantener el balance. Sabemos profesionalmente que lo que podemos lograr en la consulta es moderado o inclusive mínimo en el contexto en el que vivimos. Uno se cuestiona si es ético proporcionarles la ilusión de que su condición mejorará con el tratamiento, porque muchas veces somos conscientes de que, si no cambia el contexto, las chances a que, por ejemplo, la depresión se les mejore o las adicciones se controlen, son bajas. (Profesional sanitario 733, comunicación personal, 2019)

Algunos de estos proveedores reaccionaban estratégicamente a estas restricciones, diseñando programas comunitarios para afrontar los problemas de una manera más amplia, o participando en movimientos sociales y acciones políticas que demandaban y generaban la mejora de las condiciones de vida, así como los derechos de comunidades migrantes y marginales. Otros, lamentablemente, atravesaban procesos de agotamiento profesional (Síndrome de burnout) que, en lo general, resultaban en ajustes para continuar con su ocupación dedicándola a otro público (más típica en médicos y psicólogos trabajando en ámbitos más flexibles) o en cambios de carrera (más común en el caso de trabajadores voluntarios, abundantes en el campo de la provisión de servicios a migrantes en organizaciones sin fines de lucro, o jóvenes que iniciaban su dedicación laboral y terminaban buscando tareas más amenas).

Lógicamente, nuestra investigación reveló que los proveedores de servicios sanitarios y migratorios con formación en salud migrante, sensibles a la práctica intercultural e interdisciplinaria, de inclinación progresista o ideológica y políticamente más abiertos, y comprometidos con los derechos humanos (además, claro está, de los migrantes) condujeron mejor a los migrantes y familiares en la superación de sus problemas. Asimismo, los migrantes y familiares que reportaron positivamente la atención recibida enfatizaron la sensibilidad de las personas que los atendieron y también la importancia de su persistencia e inventiva como agentes en la facilitación de servicios (sobre todo si existían barreras o surgían imprevistos). El encontrarse y conectarse con este tipo de personas adquiría entonces un valor trascendental en las vidas de los migrantes y sus familiares, dadas las faltas estructurales que, claramente, deben ser rectificadas. 


\section{Reflexiones finales}

La aplicación del prisma crítico, interdisciplinario, transnacional y activista al estudio de la salud migrante, a través del caso ecuatoriano, condujo a la comprensión, revisión y descubrimiento de procesos que migrantes y familiares no migrantes atraviesan frecuentemente. $\mathrm{Al}$ (re)conceptualizarlos y enmarcarlos sociológicamente, se ha intentado que migrantes, familiares y proveedores de servicios puedan, por un lado, identificar, nombrar y entender lo que les ha sucedido y, por otro, prevenir y lidiar con los problemas de un modo más eficaz, evitando, idealmente, que lleguen a un punto de severidad mayor. Para que este aporte rinda sus frutos, y en línea con las metas del activismo académico, se ha estado trabajando en su difusión, a través de los medios académicos tradicionales, medios masivos de comunicación (incluyendo el lanzamiento de una página de internet con materiales informativos y bibliografía gratuitamente accesibles ${ }^{8}$ ) y la organización de talleres formativos comunitarios y profesionales. Las articulaciones para influenciar el diseño de programas y la reforma de políticas sanitarias y migratorias que tengan en cuenta estos factores están aún por desarrollarse, pero se cree que al menos la realización de este estudio y su difusión contienen, en sí mismos, la posibilidad de que el conocimiento generado tenga su impacto en quienes están vinculados a esas tareas directamente.

En este trabajo, he presentado una síntesis de los resultados hasta ahora obtenidos a partir de la cual quisiera, para concluir, ofrecer unas reflexiones sobre las preguntas teóricas originalmente planteadas. Primero, el análisis de las experiencias migratorias y del desarrollo de la salud de los migrantes y sus familiares no migrantes devela que las desigualdades sociales, a lo largo de las intersecciones de raza, etnia, nacionalidad, estado migratorio, género, sexualidad y clase, tienen, sin duda, un impacto que se ve reflejado en el modo en que migrantes y familiares enmarcan sus historias, comprenden sus contextos, interactúan e imaginan futuros. Ningún factor actúa por sí mismo ni predetermina las acciones o el devenir; sin embargo, empalmados afectan subjetiva y estructuralmente las experiencias de vida de cada persona. Estas matrices sociales de poder atraviesan los procesos migratorios y de salud, abriendo y cerrando caminos, afectando así el bienestar de migrantes y familiares. Lo más notable a tener en cuenta, a partir de esta investigación, es cómo múltiples matrices cambian y viajan de un lugar a otro, y cómo la introyección de esas jerarquías móviles

8. El diseño de materiales informativos y la realización de la página de internet también se está desarrollando de manera interdisciplinar. Actualmente, la creación de estos materiales está siendo realizada con la colaboración de estudiantes de Sociología, Gobierno y Política, Estudios Latinoamericanos, Diseño y Fotografía de St. John's University, y de un artista asociado al proyecto. Me fue otorgado un premio del Comité de Acción Social de Sociologists for Women in Society en reconocimiento a esta iniciativa. 
afecta la capacidad de agencia. Se observa, por ejemplo, cómo migrantes rehacen su concepción de género y sexualidad, atraviesan desafiantes procesos de racialización basados en distintos marcos etno-nacionales, revalorizan escalas socioeconómicas $\mathrm{y}$, así, replantean su capacidad de acción individual y colectiva.

Segundo, el estudio de experiencias migratorias y sanitarias de ecuatorianos en España y Estados Unidos, así como de familiares no migrantes y retornados en Ecuador, muestra cómo las disparidades estructurales, reflejadas en el grado de inclusión y sensibilidad a la salud migrante de políticas migratorias y sanitarias, y culturalmente en el tipo de apertura a la diversidad, afectan el desarrollo de problemas psicológicos y físicos, el acceso a y tipo de servicios obtenidos por migrantes y familiares, además de la incidencia de la marginalización interpersonal en la provisión de servicios. La violencia básica inherente a cualquier tipo de desigualdad acompaña a los procesos migratorios (usualmente resultantes de situaciones apremiantes e incrementalmente plagados de desafíos durante y después del viaje), y se manifiesta en la salud personal, familiar y comunitaria, la cual, a su vez, refleja las mismas injustas desigualdades.

Tercero, nuestro estudio y revisión crítica de la literatura en el tema de salud y migración deja en claro que no solo las ideologías, sino también su arraigamiento estructural, influencian el diseño de programas sanitarios, currículos educativos, investigaciones científicas, en general, y la conceptualización misma del bienestar del migrante y la definición de trastornos a la salud y enfermedades, en particular. Nuestro aporte pone en evidencia cómo esto sucede y está normalizado, y propone nuevas conceptualizaciones con el objetivo de crear más apertura sociocultural, fomentar la formación profesional y la creación de programas y políticas adecuados, además de, en última instancia, promover el bienestar de comunidades migrantes y la salud colectiva.

Cuarto, el estudio comparativo realizado vislumbra la manera en que políticas migratorias excluyentes impulsan la marginalidad y jerarquización de migrantes en varias categorías (irregular, refugiado, asilado, residente, etc.), y (re)victimizan a quienes no logran regularizar su estatus. Estos procesos solo alimentan las amenazas y riesgos migratorios, incrementando la vulnerabilidad de los migrantes a sufrir trastornos de salud y barreras a su tratamiento, empeorando así las desigualdades entre poblaciones migrantes y no migrantes en los países de destino y debilitando la salud colectiva.

Quinto, nuestra investigación también enfatiza la capacidad de migrantes, familiares y proveedores de servicios a quebrar con estructuras y prácticas nocivas, analizando sus tácticas de adaptación, resistencia, resiliencia y cambio. Sin exagerar o romantizar estas acciones, vemos que, sin duda, son fundamentales para revertir 
procesos insalubres y de marginalización. En general, observamos que, colectivamente, los proveedores de servicios se han organizado más que los migrantes y familiares para la demanda y promoción de mejores condiciones y políticas migratorias y sanitarias. Sin embargo, los migrantes y familiares tienden a la opción colectiva a un nivel más íntimo y familiar, generalmente asociado a su condición irregular o precaria. Por último, nuestro estudio reafirma la importancia de realizar este tipo de investigaciones activistas críticas transnacional e interdisciplinariamente, a pesar de las dificultades logísticas que puedan presentar, ya que brindan no solo una riqueza de información única, sino que tienen el potencial de generar alternativas eficaces para lidiar con los problemas e injusticias encontradas de un modo comprehensivo.

\section{Referencias}

Abraído-Lanza, Ana; Dohrenwend, Bruce; Ng-Mak, Daisy; Turner, Blake (1999). The Latino Mortality Paradox: a Test of the "Salmon Bias" and Healthy Migrant Hypotheses. American Journal of Public Health, 89(10), 1543-1548.

Achotegui, Joseba (2004). Emigrar en situación extrema: el síndrome del inmigrante con estrés crónico y múltiple (Síndrome de Ulises). Revista Norte de Salud Mental, 21, 39-52.

Achotegui, Joseba (2009). Ulysses Syndrome. The Immigrant Syndrome of Chronic and Multiple Stress. Barcelona: El mundo de la mente.

Acker, Joan (2006). Inequality Regimes Gender, Class, and Race in Organizations. Gender and Society, 2O(4), 441-464.

Agustín, Laura (2006). Atreverse a cruzar fronteras: migrantes como protagonistas. Viento Sur, 87, 73-82.

Agustín, Laura (2007). Sex at the Margins: Migration, Labour Markets and the Rescue Industry. London: Zed Books.

Almeida-Filho, Naomar (1989). Epidemiologia Sem Números: Uma Introducao Crítica a Ciencia Epidemiológica. Rio de Janeiro: Campus.

Almeida-Filho, Naomar (2000). La ciencia tímida: ensayos de deconstrucción de la epidemiología. Buenos Aires: Lugar Editorial.

Biehl, João; Petryna, Adriana (2013). When People Come First: Critical Studies in Global Health. Princeton: Princeton University Press.

Bourbeau, Philippe (2015). Migration, Resilience, and Security: Responses to New Inflows of Asylum Seekers and Migrants. Journal of Ethnic and Migration Studies, 41(12), 1958-1977. 
Breilh, Jaime (1977). Crítica a la interpretación capitalista de la epidemiología: un ensayo de desmitificación del proceso salud-enfermedad. México: UAM-X.

Breilh, Jaime (2003). Epidemiología crítica: Ciencia emancipadora e interculturalidad. Buenos Aires: Lugar Editorial.

Breilh, Jaime (2010a). Epidemiología: economía política y salud (7. ${ }^{\mathrm{a}}$ ed.). Quito: Corporación Editora Nacional/Universidad Andina Simón Bolívar.

Breilh, Jaime (2010b). Las 3 'S ' de la determinación de la vida: 10 tesis hacia una versión crítica de la determinación social de la vida y la salud. En Determinação Social da Saúde e Reforma Sanitária (pp. 87-125), editado por Roberto Nogueira. Rio de Janeiro: CEBES.

Breilh, Jaime (2013). La determinación social de la salud como herramienta de transformación hacia una nueva salud pública (salud colectiva). Rev Nac Salud Pública, 31(supl. 1), S13-S27.

Brown, Tim; Andrews, Gavin; Cummins, Steven; Greenhough, Beth; Lewis, Daniel; Power, Andrew (2017). Health Geographies: A Critical Introduction. Chichester, UK; Hoboken, NJ: Wiley-Blackwell.

Cabieses, Baltica (2014). La compleja relación entre posición económica, estatus migratorio y resultados de salud. Value in Health Regional Issues, 5, 1-6.

Caplan, Susan (2007). Latinos, Acculturation, and Acculturative Stress: A Dimensional Concept Analysis. Policy, Politics, \& Nursing Practice, 8(2), 93-106.

Castles, Stephen (2009). Development and Migration - Migration and Development: What Comes First? Theoria: A Journal of Political and Social Theory, $56(121), 1-31$.

Castro, Arachu; Singer, Merrill (Eds.), (2004). Unhealthy Health Policy: A CriticalAnthropological Examination. Maryland: Altamira Press.

Cho, Sumi; Crenshaw, Kimberlé Williams; McCall, Leslie (2013). Toward a Field of Intersectionality Studies: Theory, Applications, and Praxis. Signs, 38(4), 785-810.

Crenshaw, Kimberlé Williams (1995). Mapping the Margins: Intersectionality, Identity Politics, and Violence Against Women of Color. En Critical Race Theory: The Key Writings that Formed the Movement (pp.357-383), editado por Kimberlé Williams Crenshaw; Neil Gotanda; Garry Peller; Kendall Thomas. New York: The New Press.

Crenshaw, Kimberlé Williams; Gotanda, Neil; Peller, Garry; Thomas, Kendall (Eds.), (1995). Critical Race Theory: The Key Writings that Formed the Movement. New York: The New Press.

Cuestas, Fedra (2011). Sobre locura y emigración en el mundo globalizado. Psicoperspectivas, 1O(1), 21-45. Recuperado de http://www.scielo.cl/scielo.php?script=sci_arttext\&pi$\mathrm{d}=$ So718-69242011000100003\&lng=es\&tlng=es. 10.5027/psicoperspectivas-Vol1o-Issue1-fulltext-137 
Donnangelo, Maria Cecília (1979). Saúde e sociedade. Sao Paulo: Duas Cidades.

Eschbach, Karl; Ostir, Glenn; Patel, Kushang; Markides, Kyryakos; Goodwin, James (2004). Neighborhood Context and Mortality Among Older Mexican Americans: Is There a Barrio Advantage? American Journal of Public Health, 94(10), 1807-1812.

Esterberg, Kristin (2002). Qualitative Methods in Social Research. New York: McGraw-Hill.

Falconí-Trávez, Diego (Ed.), (2014). "Me fui a volver": narrativas, autorías y lecturas teorizadas de las migraciones ecuatorianas. Quito: Corporación Editora Andina/Universidad Andina Simón Bolívar.

Farmer, Paul (2001). Infections and Inequalities: The Modern Plagues. Berkeley: University of California Press.

Farmer, Paul; Kleinman, Arthur; Yong-Kim, Jim; Basilico, Matthew (Eds.), (2017). Reimagining Global Health: An Introduction. Berkeley: University of California Press.

Freund, Peter; McGuire, Meredith; Podhurst, Linda (2002). Health, Illness, and the Social Body: A Critical Sociology $\left(4^{\mathrm{a}} \mathrm{ed}\right.$.). New Jersey: Prentice Hall.

Geraci, Salvatore (2006). La syndrome di Salgari 20 anni doppo. Janus. Medicina: Cultura, Culture, 21, 21-29.

Glenn, Evelyn (200o). Citizenship and Inequality: Historical and Global Perspectives. Social Problems, 47(1), 1-20.

Hale, Charles (Ed.), (2008). Engaging Contradictions: Theory, Politics, and Methods of Activist Scholarship. Los Angeles: University of California Press.

Haney-Lopez, Ian (1996). White by Law: The Legal Construction of Race. New York: New York University Press.

Hankivsky, Olena; Christoffersen, Ashlee (2008). Intersectionality and the Determinants of Health: A Canadian Perspective. Critical Public Health, 18(3), 271-283.

Herrera, Gioconda (Coord.), (2008). Ecuador: la migración internacional en cifras. Quito: UNFPA/FLACSO.

Hill-Collins, Patricia (1986). Learning from the Outsider Within: The Sociological Significance of Black Feminist Thought. Social Problems, 33(6), S14-S32.

Hill-Collins, Patricia (1998). Fighting Words: Black Women and the Search for Justice. Minneapolis: University of Minnesota Press.

Hing, Bill Ong (2004). Defining America Through Immigration Policy. Philadelphia: Temple University Press. 
Horvath, Steve; Gurven, Michael; Levine, Morgan; Trumble, Benjamin; Kaplan, Hillard; Allayee, Hooman; Ritz, Beate...; Assimes, Themistocles (2016). An epigenetic clock analysis of race/ ethnicity, sex, and coronary heart disease. Genome Biology, 17. https://doi.org/10.1186/ s13059-016-1030-0

Illingworth, Patricia; Parmet, Wendy (2017). The Health of Newcomers: Immigration, Health Policy, and the Case for Global Solidarity. New York: NYU Press.

International Organization for Migration (2013). International Migration, Health and Human Rights. Geneve: IOM.

International Organization for Migration (2018). Migration Health Annual Report 2016. Geneve: IOM.

Iriart, Celia; Waitzkin, Howard; Breilh, Jaime; Estrada, Alfredo; Merhy, Emerson Elías (2002). Medicina social latinoamericana: aportes y desafíos. Rev Panam Salud Publica/Pan Am J Public Health, 12(2), 128-136.

Jaggar, Alison (2008). Just Methods: An Interdisciplinary Feminist Reader. Boulder: Paradigm Publishers.

Johnson, Kevin (2007). Opening the Floodgates: Why America Needs to Rethink its Borders and Immigration Laws. New York: New York University Press.

Jokisch, Brad (2014). Ecuador: From Mass Emigration to Return Migration? Migration Policy Institute. Recuperado de http://migrationpolicy.org/article/ecuador-mass-emigration-return-migration

Krieger, Nancy (2012). Epidemiology and the People's Health: Theory and Context. New York: Oxford University Press.

La Parra-Casado, Daniel; Mateo-Pérez, Miguel Ángel; Albert-Guardiola, María Carmen; López, Susana (2007). Estado de salud y demanda de servicios de salud de la población ecuatoriana en España. Inguruak, 44, 193-208. Recuperado de http://dialnet.unirioja.es/ servlet/articulo? codigo $=2572553$

Lara, Mariaelena; Gamboa, Cristina; Kahramanian, M. Iya.; Morales, Leo S.; Hayes-Bautista, David E. (2005). Acculturation and Latino Health in the United States: A Review of the Literature and its Sociopolitical Context. Annual Review of Public Health, 26, 367-397.

Laurell, Asa Cristina (1982). La salud-enfermedad como proceso social. Revista Latinoamericana de Salud, 2, 7-25.

Mahmood, Saba (2001). Feminist Theory, Embodiment, and the Docile Agent: Some Reflections on the Egyptian Islamic Revival. Cultural Anthropology, 12, 202-236. 
Mani, Lata (1998). Contentious Traditions: The Debate on Sati in Colonial India. Berkeley: University of California Press.

Martínez-Andrade, Luis (2019). Feminismos a la contra: entre-vistas al sur global. Santander: La Vorágine.

Menon, Ritu; Bhasin, Kamla (1998). Borders and Boundaries: Women in India's Partition. New Jersey: Rutgers University Press.

Meñaca, Arantxa (2006). Familias rotas y problemas de salud. La medicalización de las familias migrantes ecuatorianas. Quaderns de l'Institut Català d'Antropologia, 22, 161-178.

Miranda, Jeanne; Siddique, Juned; Der-Martirosian, Claudia; Belin, Thomas (2005). Depression among Latina Mothers Separated from their Children. Psychiatric Services, 56(6), 717-720.

Mooney, Erin (2005). The Concept of Internal Displacement and the Case for Internally Displaced Persons as a Category of Concern. Refugee Survey Quarterly, 24(3), 9-26.

Naples, Nancy (2003). Feminism and Method: Ethnography, Discourse Analysis, and Activist Research. New York: Routledge.

Navarro, Vicente (2009). What We Mean by the Social Determinants of Health. International Journal of Health Services, 39(3), 423-441.

Navarro, Vicente; Shi, Leiyu (2001). The Political Context of Social Inequalities and Health. Social Science or Medicine, 52(3), 481-491.

Nazroo, James Y. (2003). The Structuring of Ethnic Inequalities in Health: Economic Position, Racial Discrimination, and Racism. American Journal of Public Health, 93(2), 277-284.

Ong, Aihwa (1999). Cultural Citizenship as Subject Making: Immigrants Negotiate Racial and Cultural Boundaries in the U.S. En Race, Identity, and Citizenship: A Reader (pp. 262293), editado por Rodolfo D. Torres; Louis F. Mirón; Jonathan Xavier Inda. Malden, MA: Blackwell Publishing.

Organización Mundial de la Salud (2017). Preguntas frecuentes sobre saludy migración. Recuperado de https://www.who.int/features/qa/88/es/

Ortner, Sherry (2006). Anthropology and Social Theory: Culture, Power and the Acting Subject. Durham: Duke University Press.

Pribilsky, Jason (2004). "Aprendemos a convivir": Conjugal Relations, Co-parenting, and Family Life Among Ecuadorian Transnational Migrants in New York and The Ecuadorian Andes. Global Networks, 4, 313-334.

Pribilsky, Jason (2007). La Chulla Vida: Gender, Migration and the Family in Andean Ecuador and New York City. Syracuse: Syracuse University Press. 
Ramírez, Jacques (2013). La política migratoria en Ecuador: rupturas, tensiones, continuidadesy desafios. Quito: Editorial IAEN.

Raphael, Dennis (2009). Social Determinants of Health: Canadian Perspectives. Toronto: Canadians' Scholars Press.

Renzaho, Andre (Ed.), (2016). Globalisation, Migration and Health: Challenges and Opportunities. Londres: Imperial College Press.

Ríos-Marín, Alexandra; Hernández-Londoño, Lina. (2014) Descripción de procesos migratorios en Almería-España y su repercusión en la salud mental. Revista de la Facultad Nacional de Salud Pública,32(supl. 1), S67-S77.

Roberts, Dorothy (2002). Shattered Bonds: The Color of Child Welfare. New York: Basic Civitas Books.

Romero, Mary (2008). Crossing the Immigration and Race Border: A Critical Race Theory Approach to Immigration Studies. Contemporary Justice Review, 11(1), 23-37.

Romero, Mary (2011). The Maid's Daughter: Living Inside and Outside the American Dream. New York: New York University Press.

Rubalcava, Luis. N.; Teruel, Graciela; Thomas, Duncan; Goldman, Noreen (2008). The Healthy Migrant Effect: New Findings from the Mexican Family Life Survey. American Journal of Public Health, 98(1), 78-84.

Samaja, Juan (1992) Epistemología y epidemiología. Campinas: Congreso Brasileño de Epidemiología.

Sanchez, Gabriella; Romero, Mary (2010). Critical Race Theory in the US Sociology of Immigration. Sociology Compass, 4, 779-788.

Sayad, Abdelmalek (2007). The Suffering of the Immigrant. Cambridge: Polity Press.

Segato, Rita (2003). Las estructuras elementales de la violencia. Ensayos sobre género entre la antropología, el psicoanálisis y los derechos humanos. Buenos Aires: Prometeo/Universidad Nacional de Quilmes.

Segato, Rita (2016). La crítica de la colonialidad en ocho ensayos. Buenos Aires: Prometeo.

Shayne, Julie (Ed.), (2014). Taking Risks: Feminists, Activism, and Activist Research in the Americas. Albany: SUNY Press.

Singer, Merrill; Baer, Hans (2017). Critical Medical Anthropology (2. ${ }^{\mathrm{a}}$ ed.). New York: Routledge.

Southwick, Steven; Bonanno, George; Masten, Ann; Panter-Brick, Catherine; Yehuda, Rachel (2014). Resilience Definitions, Theory, and Challenges: Interdisciplinary Perspectives. European Journal of Psychotraumatology, 5. https://doi.org/10.3402/ejpt.v5.25338 
Spivak, Gayatri (1988). Can the Subaltern Speak? En Marxism and the interpretation of culture (pp. 271-313), editado por Cary Nelson. Urbana: University of Illinois Press.

The Health Initiative of the Americas (2017). The Health Initiative of the Americas Fact Sheet. Berkeley:School of Public Health. Recuperado de https://hiaucb.files.wordpress.com/2017/11/ hia_factsheet_2pages_nov2017_spanish.pdf

Turra, Cassio; Elo, Irma (2008). The Impact of Salmon Bias on the Hispanic Mortality Advantage: New Evidence from Social Security Data. Population Research and Policy Review, $27(5), 515-530$.

Ullman, Heidi; Goldman, Noreen; Massey, Douglass (2011). Healthier Before They Migrate, Less Healthy when they Return? The Health of Return Migrants in Mexico. Social Science and Medicine, 73(3), 421-428.

Villalón, Roberta (2010a). Violence against Latina Immigrants: Citizenship, Inequality, and Community. New York: New York University Press.

Villalón, Roberta (2010b). Passage to Citizenship and the Nuances of Agency: Latina Battered Immigrants. Women's Studies International Forum, 33(6), 552-560.

Villalón, Roberta (2011). Feminist Activist Research and Strategies from within the Battered Immigrant Women's Movement. Interface: a journal for and about social movements, 3(2), 246-270.

Villalón, Roberta (2014). Latina Battered Immigrants, Citizenship and Inequalities: Reflections on Activist Research. En Taking Risks: Feminists, Activism, and Activist Research in the Americas (pp. 245-277), editado por Julie Shayne. Albany: SUNY Press.

Villalón, Roberta (2015). Violence Against Immigrants in a Context of Crisis: A Critical Migration Feminist of Color Analysis. Journal of Social Distress and the Homeless, 24(3), 116-139.

Waitzkin, Howard; Iriart, Celia; Estrada, Alfredo; Lamadrid, Silvia (2001). Social Medicine Then and Now: Lessons from Latin America. American Journal of Public Health, 91(10), 1592-1601.

Williams, Gareth (2003). The Determinants of Health: Structure, Context and Agency. Sociology of Health \& Illness, 25(3), 131-154.

World Health Organization (2019). Promoting the Health of Refugees and Immigrants: Draft Global Action Plan 2019-2023. Report by the Director-General. Recuperado de https://apps. who.int/gb/ebwha/pdf_files/WHA72/A72_25-en.pdf 